Mathematical Modelling AND ANALysis

Volume 18 Number 4, September 2013, 537-542

http://dx.doi.org/10.3846/13926292.2013.839963

(c) Vilnius Gediminas Technical University, 2013
Publisher: Taylor\&Francis and VGTU

http://www.tandfonline.com/TMMA

Print ISSN: 1392-6292

Online ISSN: 1648-3510

\title{
Convergence of a Cyclic Algorithm for the Split Common Fixed Point Problem Without Continuity Assumption
}

\section{Fenghui Wang and Huanhuan Cui}

\author{
Luoyang Normal University \\ Longmen Road 71, 471022 Luoyang, China \\ E-mail(corresp.): wfenghui@gmail.com \\ E-mail: hhcui@live.cn
}

Received September 12, 2012; revised June 20, 2013; published online September 1, 2013

\begin{abstract}
In their recent paper (Math. Model. Anal., 17(4):457-466, 2012), Tang, Peng and Liu proposed a cyclic algorithm for solving the split common fixed point problem and established its weak convergence under some certain conditions. In this paper, we shall present a simple proof of such a result and moreover we shall remove one condition, continuity of the mapping involved, ensuring the convergence of the algorithm.
\end{abstract}

Keywords: directed mapping, split common fixed point problem, demicontractive mapping.

AMS Subject Classification: 49J53; 65K10.

\section{Introduction}

The split feasibility problem (SFP) [6] is formulated as finding

$$
x \in C, \quad \text { s.t. } \quad A x \in Q \text {, }
$$

where $C$ and $Q$ are respectively closed convex subsets in Hilbert spaces $H_{1}$ and $H_{2}$, and $A: H_{1} \rightarrow H_{2}$ is a bounded linear mapping. The SFP has been widely studied by many authors (see $[3,8,11,13,14,15,16,17]$ ), due to its various applications in the real word application $[4,5]$. An efficient algorithm for solving the SFP is Byrne's CQ algorithm: for any $x_{0} \in H_{1}$ the CQ algorithm generates an iterative sequence as

$$
x_{n+1}=P_{C}\left(I+\gamma A^{*}\left(P_{Q}-I\right) A\right) x_{n},
$$

where $0<\gamma<2 /\|A\|^{2}$, and $P_{C}$ denotes the projector onto $C$. It is known that the CQ algorithm converges weakly to a solution of the SFP if such a solution exists. 
In the case whenever both $C$ and $Q$ consist of fixed point sets of some nonlinear mappings, the SFP is known as the two-sets split common fixed point problem (SCFP). More specifically, the two-sets SCFP requires to find

$$
x \in \operatorname{Fix}(U), \quad \text { s.t. } \quad A x \in \operatorname{Fix}(T),
$$

where $\operatorname{Fix}(U)$ and $\operatorname{Fix}(T)$ stand for respectively the fixed point sets of $U: H_{1} \rightarrow H_{1}$ and $T: H_{2} \rightarrow H_{2}$. We note that to implement the CQ algorithm one has to calculate the metric projection at each iteration. However, it is hard to calculate the metric projection whenever the corresponding closed convex subset is fixed point set. Therefore the CQ algorithm does not work for the two-sets SCFP. Alternatively, Censor and Segal [7] introduced the following algorithm:

$$
x_{n+1}=U\left(I-\gamma A^{*}(I-T) A\right) x_{n},
$$

to solve the two-sets SCFP for directed mappings. Subsequently, Moudafi [10] considered (1.1) for demicontractive mappings and proposed the following algorithm:

$$
\left[\begin{array}{l}
u_{n}=x_{n}-\gamma A^{*}(I-T) A x_{n}, \\
x_{n+1}=\left(1-\alpha_{n}\right) u_{n}+\alpha_{n} U u_{n}
\end{array}\right.
$$

It is known that demicontractive mappings properly include directed mappings. So in this sense, the Moudafi's algorithm (1.3) is an extension of algorithm (1.2).

Note that the two-sets SCFP is just a special case of the SCFP. More specifically, the general SCFP requires to find

$$
x \in \bigcap_{i=1}^{p} \operatorname{Fix}\left(U_{i}\right), \quad \text { s.t. } \quad A x \in \bigcap_{j=1}^{s} \operatorname{Fix}\left(T_{j}\right),
$$

where $U_{i}: H_{1} \rightarrow H_{1}, i=1, \ldots, p$ and $T_{j}: H_{2} \rightarrow H_{2}, j=1, \ldots, s$ are two classes of nonlinear mappings. Recently Tang, Peng and Liu [12] considered the SCFP for demicontractive mappings and proposed a cyclic algorithm:

$$
\left[\begin{array}{l}
u_{n}=x_{n}-\gamma A^{*}\left(I-T_{\mathrm{j}(n)}\right) A x_{n}, \\
x_{n+1}=\left(1-\alpha_{n}\right) u_{n}+\alpha_{n} U_{\mathrm{i}(n)} u_{n},
\end{array}\right.
$$

where $\mathrm{i}(n):=n \bmod p+1$ and $\mathrm{j}(n):=n \bmod s+1$. Clearly, the above algorithm is a further generalization of Moudafi's algorithm (1.3). Under some mild assumptions they established the weak convergence of their algorithm to a solution of the SCFP whenever such a solution exists.

We note that in [12] the continuity of the mappings $U_{i}$ and $T_{j}$ is one of conditions that ensures the convergence of algorithm (1.5). However the convergence of Moudafi's algorithm (1.3) does not need such a condition and more importantly many nonlinear mappings, such as directed and demicontractive mappings, are discontinuous in general [9]. In this short paper, we shall restate the weak convergence of algorithm (1.5) but we present a simple proof and moreover we can remove the continuity condition. 


\section{Preliminary and Notation}

Throughout, let $I$ denote the identity mapping, $\operatorname{Fix}(T)$ denote the set of the fixed points of an mapping $T$, and let $\omega_{w}\left(x_{n}\right)$ denote the set of weak cluster points of the sequence $\left\{x_{n}\right\}$. The notation " $\rightarrow$ " stands for strong convergence and " $\rightarrow$ " stands for weak convergence.

Let $T: H_{1} \rightarrow H_{1}$ be a mapping with $\operatorname{Fix}(T) \neq \emptyset$. Then $I-T$ is called demiclosed at zero if $x_{n} \rightarrow x,(I-T) x_{n} \rightarrow 0 \Rightarrow x=T x$. Let $C$ be a closed convex nonempty subset and $\left\{x_{n}\right\}$ be a sequence in $H_{1}$. The sequence $\left\{x_{n}\right\}$ is called Fejér monotone with respect to $C$, if

$$
\left\|x_{n+1}-c\right\| \leq\left\|x_{n}-c\right\|, \quad \forall c \in C .
$$

Lemma 1 [Bauschke-Borwein [1]]. If the sequence $\left\{x_{n}\right\}$ is Fejér monotone with respect to $C$, then $x_{n} \rightarrow x^{*} \in C$ if and only if $\omega_{w}\left(x_{n}\right) \subseteq C$.

A mapping $T: H_{1} \rightarrow H_{1}$ is called $\tau$-demicontractive $(\tau<1)$ if

$$
\|T x-z\|^{2} \leq\|x-z\|^{2}+\tau\|x-T x\|^{2}, \quad \forall x \in H_{1}, y \in \operatorname{Fix}(T)
$$

or equivalently

$$
\langle x-z, T x-x\rangle \leq \frac{\tau-1}{2}\|x-T x\|^{2}, \quad \forall x \in H_{1}, y \in \operatorname{Fix}(T) .
$$

In particular, $T$ is called quasi-nonexpansive if $\tau=0$ and directed if $\tau=-1$ (cf. $[2,7,9])$.

Lemma 2. Let $\mathrm{T}: \mathrm{H}_{2} \rightarrow \mathrm{H}_{2}$ be a $\tau$-demicontractive mapping, $\mathrm{A}: \mathrm{H}_{1} \rightarrow \mathrm{H}_{2}$ be a linear bounded mapping and let $V_{\lambda}:=I-\lambda A^{*}(I-T) A$ with $0<\lambda<$ $(1-\tau) /\|A\|^{2}$. Then

$$
\left\|V_{\lambda} x-z\right\|^{2} \leq\|x-z\|^{2}-\lambda\left(1-\tau-\lambda\|A\|^{2}\right)\|T x-x\|^{2}
$$

for all $x \in H_{1}$ and all $z \in A^{-1}(\operatorname{Fix}(T))=\{y: A y \in \operatorname{Fix}(T)\}$.

Proof. Given $x \in H$ and $z \in A^{-1}(\operatorname{Fix}(T))$, we have

$$
\left\|V_{\lambda} x-z\right\|^{2}=\|x-z\|^{2}-2 \lambda\left\langle x-z, A^{*}(I-T) A x\right\rangle+\lambda^{2}\left\|A^{*}(I-T) A x\right\|^{2} .
$$

Since $A z \in \operatorname{Fix}(T)$ and

$$
2\left\langle x-z, A^{*}(I-T) A x\right\rangle=2\langle A x-A z,(I-T) A x\rangle,
$$

it follows from inequality (2.1) that

$$
2\left\langle x-z, A^{*}(I-T) A x\right\rangle \geq(1-\tau)\|(I-T) A x\|^{2} .
$$

Substituting this into (2.2) we have

$$
\left\|V_{\lambda} x-z\right\|^{2} \leq\|x-z\|^{2}-\lambda(1-\tau)\|(I-T) A x\|^{2}+\lambda^{2}\left\|A^{*}(I-T) A x\right\|^{2} .
$$

Therefore the desired inequality follows from the fact that $\left\|A^{*} y\right\| \leq\|A\|\|y\|$, $\forall y \in H_{2}$. 


\section{Weak Convergence Theorem}

Assumption 1. We assume the following conditions on problem (1.4):

- The solution set to (1.4), denoted by $\mathcal{S}$, is nonempty;

- $I-U_{i}, i=1, \ldots, p$ and $I-T_{j}, j=1, \ldots, s$ are demiclosed at 0 ;

- $U_{i}(1 \leq i \leq p)$ is $\nu_{i}$-demicontractive and $T_{j}(1 \leq j \leq s)$ is $\tau_{i}$-demicontractive.

Let now $\nu:=\max _{1 \leq i \leq p} \nu_{i}$ and $\tau:=\max _{1 \leq j \leq s} \tau_{j}$. Clearly $U_{i}$ is $\nu$-demicontractive for all $1 \leq i \leq p$ and $T_{j}$ is $\tau$-demicontractive for all $1 \leq j \leq s$.

Theorem 1. Let Assumption 1 be satisfied, $\gamma \in\left(0,(1-\tau) /\|A\|^{2}\right)$ and $\left\{\alpha_{n}\right\} \subseteq$ $[\epsilon, 1-\nu-\epsilon]$ with $\epsilon$ a sufficiently small number. If $\mathcal{S} \neq \emptyset$, then the sequence $\left\{x_{n}\right\}$, generated by (1.5), converges weakly to some $x^{*} \in \mathcal{S}$.

Proof. Take $z \in \mathcal{S}$. It then follows from inequality (2.1) that

$$
\begin{aligned}
\left\|u_{n}-z\right\|^{2} & =\left\|x_{n}-\gamma A^{*}\left(I-T_{\mathrm{j}(n)}\right) A x_{n}-z\right\|^{2} \\
& \leq\left\|x_{n}-z\right\|^{2}-\gamma\left(1-\tau-\gamma\|A\|^{2}\right)\left\|\left(I-T_{\mathrm{j}(n)}\right) A x_{n}\right\|^{2}
\end{aligned}
$$

and also that

$$
\begin{aligned}
\left\|x_{n+1}-z\right\|^{2} & =\left\|u_{n}-z+\alpha_{n}\left(U_{\mathrm{i}(n)} u_{n}-u_{n}\right)\right\|^{2} \\
& =\left\|u_{n}-z\right\|^{2}+2 \alpha_{n}\left\langle u_{n}-z, U_{\mathrm{i}(n)} u_{n}-u_{n}\right\rangle+\alpha_{n}^{2}\left\|\left(I-U_{\mathrm{i}(n)}\right) u_{n}\right\|^{2} \\
& \leq\left\|u_{n}-z\right\|^{2}-\alpha_{n}\left(1-\nu-\alpha_{n}\right)\left\|\left(I-U_{\mathrm{i}(n)}\right) u_{n}\right\|^{2} .
\end{aligned}
$$

Let

$$
\mu:=\min \left(\gamma\left(1-\tau-\gamma\|A\|^{2}\right), \epsilon(1-\nu-\epsilon)\right)>0 .
$$

Combining the last two inequalities, we get

$$
\left\|x_{n+1}-z\right\|^{2} \leq\left\|x_{n}-z\right\|^{2}-\mu\left(\left\|\left(I-U_{\mathrm{i}(n)}\right) u_{n}\right\|^{2}+\left\|\left(I-T_{\mathrm{j}(n)}\right) A x_{n}\right\|^{2}\right) .
$$

Clearly $\left\{x_{n}\right\}$ is Fejér monotone with respect to $\mathcal{S}$, and moreover

$$
\sum_{n=0}^{\infty}\left\|\left(I-U_{\mathrm{i}(n)}\right) u_{n}\right\|^{2}<\infty, \quad \sum_{n=0}^{\infty}\left\|\left(I-T_{\mathrm{j}(n)}\right) A x_{n}\right\|^{2}<\infty .
$$

In view of Lemma 1 , to finish the proof it remains to show that $\omega_{w}\left(x_{n}\right) \subseteq \mathcal{S}$. To see this let $\hat{x} \in \omega_{w}\left(x_{n}\right)$ and let an index $j \in\{1,2, \ldots, s\}$ be fixed. Noticing that the pool of indexes is finite, we can find a subsequence $\left\{x_{m_{k}}\right\}$ of $\left\{x_{n}\right\}$ such that it converges weakly to $\hat{x}$ and $\mathrm{j}\left(m_{k}\right)=j$ for all $k$. Since, by weak continuity of $A, A x_{m_{k}}$ converges weakly to $A \hat{x}$ and

$$
\left\|\left(I-T_{j}\right) A x_{m_{k}}\right\|=\left\|\left(I-T_{\mathrm{j}\left(m_{k}\right)}\right) A x_{m_{k}}\right\| \rightarrow 0,
$$

this together with the demiclosedness of $I-T_{j}$ at zero yields $A \hat{x} \in \operatorname{Fix}\left(T_{j}\right)$. Now let an index $i \in\{1,2, \ldots, p\}$ be fixed. Similarly we can find a subsequence 
$\left\{x_{p_{k}}\right\}$ of $\left\{x_{n}\right\}$ such that it converges weakly to $\hat{x}$ and $\mathrm{i}\left(p_{k}\right)=i$ for all $k$. Noting $\left\|\left(I-T_{\mathrm{j}(n)}\right) A x_{n}\right\| \rightarrow 0$ thanks to (3.1) and by definition of $u_{n}$, we have

$$
\left\|x_{n}-u_{n}\right\| \leq \gamma\|A\|\left\|\left(I-T_{\mathrm{j}(n)}\right) A x_{n}\right\| \rightarrow 0,
$$

and thus $u_{p_{k}}$ converges weakly to $\hat{x}$. Since by $(3.1)\left\|\left(I-U_{\mathrm{i}(n)}\right) u_{n}\right\| \rightarrow 0$, the demiclosedness of $I-U_{i}$ at zero yields $\hat{x} \in \operatorname{Fix}\left(U_{i}\right)$. Altogether $\hat{x} \in \mathcal{S}$, and therefore the proof is complete.

\section{Acknowledgments}

We would like to express our sincere thanks to the referees for their valuable suggestions. The first author is supported by the National Natural Science Foundation of China $(11226227,11301253)$ and the second author is supported by the Key Foundation of Henan Educational Committee (12A110016).

\section{References}

[1] H.H. Bauschke and J.M. Borwein. On projection algorithms for solving convex feasibility problems. SIAM Rev., 38:367-426, 1996. http://dx.doi.org/10.1137/S0036144593251710.

[2] H.H. Bauschke and P.L. Combettes. A weak-to-strong convergence principle for Fejér-monotone methods in Hilbert spaces. Math. Oper. Res., 26:248-264, 2001. http://dx.doi.org/10.1287/moor.26.2.248.10558.

[3] C. Byrne. Iterative oblique projection onto convex sets and the split feasibility problem. Inverse Problems, 18:441-453, 2002.

http://dx.doi.org/10.1088/0266-5611/18/2/310.

[4] C. Byrne. A unified treatment of some iterative algorithms in signal processing and image reconstruction. Inverse Problems, 18:103-120, 2004. http://dx.doi.org/10.1088/0266-5611/20/1/006.

[5] Y. Censor, T. Bortfeld, B. Martin and A. Trofimov. A unified approach for inversion problems in intensity-modulated radiation therapy. Physics in Medicine and Biology, 51:2353-2365, 2006. http://dx.doi.org/10.1088/0031-9155/51/10/001.

[6] Y. Censor, T. Elfving, N. Kopf and T. Bortfeld. The multiple-sets split feasibility problem and its applications for inverse problems. Inverse Problems, 21:20712084, 2005. http://dx.doi.org/10.1088/0266-5611/21/6/017.

[7] Y. Censor and A. Segal. The split common fixed point problem for directed operators. J. Convex Anal., 16:587-600, 2009.

[8] J. Deepho and P. Kumam. A modified Halpern's iterative scheme for solving split feasibility problems. Abstr. Appl. Anal., 2012:Article ID 876069, 8 pp, 2012. http://dx.doi.org/10.1155/2012/876069.

[9] S. Maruster and C. Popirlan. On the Mann-type iteration and the convex feasibility problem. J. Comput. Appl. Math., 212:390-396, 2008.

http://dx.doi.org/10.1016/j.cam.2006.12.012.

[10] A. Moudafi. The split common fixed point problem for demicontractive mappings. Inverse Problems, 26:055007, 2010.

http://dx.doi.org/10.1088/0266-5611/26/5/055007. 
[11] S. Saewan and P. Kumam. Modified hybrid block iterative algorithm for convex feasibility problems and generalized equilibrium problems for uniformly quasi$\pi$-asymptotically nonexpansive mappings. Abstr. Appl. Anal., 2010:Article ID 357120, 22 pp, 2010. http://dx.doi.org/10.1155/2010/357120.

[12] Y. Tang, J. Peng and L. Liu. A cyclic algorithm for the split common fixed point problem of demicontractive mappings in Hilbert spaces. Math. Model. Anal., 17:457-466, 2012. http://dx.doi.org/10.3846/13926292.2012.706236.

[13] F. Wang and H.K. Xu. Choices of variable steps of the CQ algorithm for the split feasibility problem. Fixed Point Theory, 12:489-496, 2011.

[14] F. Wang and H.K. Xu. Cyclic algorithms for split feasibility problems in Hilbert spaces. Nonlinear Anal., 74:4105-4111, 2011. http://dx.doi.org/10.1016/j.na.2011.03.044.

[15] H.K. Xu. A variable Krasnosel'skii-Mann algorithm and the multiple-set split feasibility problem. Inverse Problems, 22:2021-2034, 2006. http://dx.doi.org/10.1088/0266-5611/22/6/007.

[16] H.K. Xu. Iterative methods for the split feasibility problem in infinite dimensional Hilbert spaces. Inverse Problems, 26:105018, 2010. http://dx.doi.org/10.1088/0266-5611/26/10/105018.

[17] Q. Yang. The relaxed CQ algorithm for solving the split feasibility problem. Inverse Problems, 20:1261-1266, 2004. http://dx.doi.org/10.1088/0266-5611/20/4/014. 